\title{
DEATH AND DYING IN MEDICINE: WHAT QUESTIONS ARE STILL WORTH ASKING?
}

\section{THE TOPIC OF DEATH AND DYING IN MEDICINE}

In the seventies, death and dying in medicine was a trendy topic for a while, having emerged from a long period of social taboo as an item of discussion. Although many of the problems that led to the rush of interest in so-called 'mortal dilemmas' of medicine remain largely unsolved, public interest has shifted to other topics. In one editor's column in a leading journal of medical ethics, the editor wrote that he would like authors to get away from their thanatological preoccupations that were taking up so much journal space, and get into the less dramatic but equally problematic issues of day-to-day decisionmaking in doctor-patient interactions.

There is wholesome sense in this admonition to steer away from the dramatic. Medical treatment in practice is often more oblique and probabilistic in how it leads to a specific outcome than the public often seems to think. Hence it may often not be justified to make the leap from describing an act of omission as 'stopping treatment' to describing the same act as 'causing death' or 'allowing death to occur'. The urge to paint a decision in more dramatic 'mortal' colors may sometimes not be helpful to clear-minded ethical discussion of the basis of the decision. So perhaps less sensationalizing of the life-or-death aspects of medical decision-making could be a salutary trend.

But if the underlying problems that led to a demand for philosophical theorizing about death and dying in medicine have not been resolved, abandonment of the topic as a serious concern could be premature. I think that the papers in this issue of Theoretical Medicine show that, while much progress has been made in some areas, basic problems have still not been solved. Two developments that show great progress are the rising hospice movement, and the emerging medico-legal consensus on brain death. But there are still many areas, especially in critical care medicine and pediatrics, ${ }^{1}$ where clear criteria for understanding decisions to forgo aggressive treatment do not appear to be easily forthcoming.

With the rise of an aging population, some of these problems are sure to get worse before they get better. With increasing technological developments paralleling the spiraling costs of health care, it is not likely that these sorts of problems will go away. Quite to the contrary. Therefore, I believe that a sustained, serious, and scholarly interest in the topic of death and dying in medicine should not be discouraged by the fact that the spotlight of public controversy seems to have moved on, for the moment, to other matters. 
Many of the dramatic controversies relating to death and dying in medicine have now been more sharply focussed down to specific problems. The papers in this issue pose controversies that are now much better defined than previously. Developments in medicine have also tended to make these problems much more concrete. They very much merit our continued scholarly attention.

Analysis of the concept of death at the philosophical level has remained much more fragmentary and incomplete. At this level of abstraction, however, perhaps it would be unduly sanguine to expect firm results. At any rate, the careful conceptual clarifications of Thomasma, Van Evra and Kluge in this issue are most helpful in consolidating some beginnings.

\section{CLARIFICATIONS}

Over and over again, in any discussion of the topic of brain death, one finds that certain basic terminological and conceptual clarifications have to be made. It is necessary to review these clarifications by way of a preliminary to informed discussion.

First, everybody allows a necessary distinction between the concept of the death of a person (an ethical or philosophical notion) and the criteria used to determine death in specific cases (medical or diagnostic criteria). The term 'brain death' is inherently ambiguous. Sometimes it refers to a concept that is a special kind of personal death, or is perhaps said to be equivalent to personal death by its exponents. Other times 'brain death' refers to a type of determination of death, a medical type of criterion that can be used to determine the death of the person, where the latter may be some 'undefined' or 'philosophical', i.e., disputable concept. Actually, the term 'brain death' in most usage probably hovers somewhere in the grey area between concept and criteria. Despite the inherent vagueness of the distinction, it is necessary to distinguish between the concept of death and the criteria used to implement the concept operationally. For further discussion, see Walton (1983).

Second, it is necessary to distinguish between brain death - meaning the irreversible destruction of the whole brain including the brainstem - on the one hand, and cerebral death - meaning destruction of the cerebral cortex on the other hand. Sometimes cerebral death is also identified with the apallic syndrome - the persistent vegetative state that affects the cortex and adjacent subcortical nuclei. The point is that a patient can have a destroyed cortex even where the brainstem is still functioning. Such patients exhibit many reflexes, e.g., breathing and swallowing, and may survive for many years without ever regaining consciousness.

One problem is that medical science cannot determine at present with certainty 
that the apallic patient might not at some future time come out of the coma. Whereas if whole brain death is properly certified by the existing medical criteria, there has been no known exception to irreversibility. ${ }^{2}$ Thus I have argued on grounds of tutiorism - in uncertainty, the safest and best known way should be followed - that cerebral death should not be identified with the death of the person (Walton 1980). At any rate, it is important to distinguish clearly between brain death and cerebral death. The latter comprises only part of the whole brain. The former is sometimes called whole brain death.

Now one can get a clearer idea of the sorts of controversies that have evolved. The advent of artificial methods of respiration and circulation has led away from the universal adherence to the traditional conception of death as the cessation of breath and circulation of the blood. Newer scientific presumptions have naturally inclined towards acceptance of the idea that irreversible destruction of the brain is the more proper notion of death. And medicine has been able to furnish criteria enabling a physician to diagnose brain death.

But to some it seems arbitrary to pick out the brain as the locus of life, or its destruction to mark the end of life. Why exclude the rest of the body? Or why not be even more specific and narrow it down to the cerebral cortex? Although brain death is now widely established, both legally and medically, its critics raise questions of philosophical import.

Although the consolidation of medical opinion on brain death has led to consensus, there is still a good deal of confusion about specific legislative wording used to define the relevant notions. Wallace-Barnhill et al. $(1982$, p. 58) point out that brain death statutes in the USA can be broken down into five different models. First, those statutes based on the Kansas model provide for alternative determinations of death based on brain death or absence of spontaneous respiratory and cardiac functions. Model two (e.g., Michigan) uses the test of absence of brain function only when the heart and lungs are artificially maintained. Model three makes no mention at all of cardiac or respiratory functions. Model four defines death as irreversible cessation of spontaneous brain function. Model five defines brain function as 'purposeful activity' as opposed to random activity of the brain (Uniform Brain Death Act, e.g., Nevada). Other states have legislation that does not fit any of these five models. So even within the brain death exponents themselves, there are unclarities and controversies about how death should be precisely defined.

One big problem is the lack of public comprehension of the new notion of brain death. A brain-dead body with a beating heart may retain much of the physical appearance of a close and loved person. Hence the idea of extending the circulation of blood and the maintenance of breathing in such a neomort for transplantation, or even for experimental purposes, may appear ghoulish and repulsive. It is hard to say why, on sober reflection, if you really accept 
the idea that a brain-dead body is no longer a person. But there it is. The idea is repulsive, and we all have to deal with that. Such neomorts could be extremely useful for many purposes of experimental medicine. ${ }^{3}$

Why do we balk at this idea? Is it a rejection of the identification of the living person with her brain? Or is it that such continued maintenance - should it become possible for longer periods - conflicts with our notions of respect for the newly dead? This is one question that philosophy needs to debate.

How far are we willing to carry this idea of brain death? Recently a braindead mother was supported artificially for a prolonged period in order to safely deliver her baby by cesarean section. The life saved seems to justify the means in this case. But is it the case that next of kin are sometimes reluctant to agree to organ transplantation from a brain-dead relative because of a deeply felt emotional reluctance to accept the idea that the loved one is truly dead? One proposal to save lives yet cope with this problem is to relieve the physicians of the need to obtain consent of the next of kin for transplantation. The proposal of Matas and Veith, in this issue, is that the physicians should be able to decide to take organs for transplantation without having to ask for direct consent of the family at the time of death. Rather, consent is presumed unless the family specifically rejects the idea, or unless the dead individual has previously registered his wish not to donate organs for transplantation purposes.

This proposal would in fact save many lives, for many now die in countries without presumed consent because of difficulties in obtaining consent for organ transplantation. Our support of the proposal will surely be conditioned in part by how we feel about brain death in relation to the death of the person. For if it is true that the person is dead when the brain is irreversibly destroyed, then surely greater discretion allowed to physicians in the right and duty to discontinue life-support systems, for purposes of salvaging organs and saving lives, is something that should be more widely accepted.

It is a good idea to point out here that many ethical concerns of daily medical practice are indirectly related to questions of death and dying. Re-defining death is not going to resolve all these problems, but it will have an effect on many of them.

\section{ISSUES IN CRITICAL CARE}

Of course the definition of death is but one major problem of ethics, medicine and law. The emerging consensus on brain death as the legally and medically appropriate conception of the death of the person has eased that problem in many ways, from a point of view of the practice of medicine. But there are many other serious problems of withdrawal of treatment where death may be 
involved, or at least at risk, that are not resolved by the use of the brain death notion.

As Jastremski and Newman point out in this issue, stopping life-support therapies where the patient is not actually dead poses the more difficult range of cases. In many such cases, aggressive therapies should be discontinued, perhaps most clearly in the cases where the competent patient refuses further treatment and the medical staff feels that treatment is not called for; but the issue is not, at least directly, one of death, or how one should define death. Yet death and dying are related to this sort of problem. For stopping treatment may contribute to, or even result in death or a shortening of life. Because the issue is a mortal one, decision-making here is always a grave matter.

As Newman points out in his paper, these problems have been greatly obfuscated by unclear use of the terms 'euthanasia', 'passive euthanasia', 'lettingdie' and so forth. Stopping treatment could seem like 'killing' if death follows. Much depends, both legally and morally, on how the 'act' or 'omission' is precisely described in a particular case. Yet omissions and the active-passive distinctions have always been extraordinarily problematic concepts both in criminal law and in moral philosophy and the theory of actions and responsibility. An act like "pulling the plug" can also be described in a negative way as a stopping of treatment, or as a not-prolonging of life. The old expression, "They also serve who only stand and wait' shows that an inaction or negative action can be described using verbs that make it seem in some ways very much like a positive act. Indeed, in criminal law, occasionally omissions can be described as positive acts, e.g., failure to yield information may (positively) force someone else to give out the information. ${ }^{4}$ Hence questions of responsibility for not treating or for stopping treatment fall into a philosophically grey area. Many philosophers even go so far as to deny that there is a morally significant difference between 'killing' and 'letting-die'.

Despite these conceptual uncertainties, decisions are daily made in intensive care units to stop treatments that could make the prolongation of life technically possible. It is quite often clear in such cases that the rigid enforcement of a policy to always continue treatment, even at great cost in pain and suffering, would be contrary to the aims of medicine and would be an affront to human dignity and compassion. ${ }^{5}$ But how is such a grave decision to be made in particular cases? Here we get into issues of autonomy of decision-making, informed consent, doctor-patient communication, and the right of a family member or proxy to speak for an incompetent person. All these fuzzy issues are of broad import for the philosophy of medicine. But all relate to the topic of death and dying, especially in the high-technology context of intensive-care decision-making. 


\section{RELATIONSHIP BETWEEN PHILOSOPHY AND MEDICINE}

A major question in the issue of defining death is the relationship between philosophy and medicine as fields of scholarship. Wikler, in his essay in this issue, points out that no consensus exists among philosophers or bioethicists on what a 'person' is. Yet the argument for brain death as the best indicator of the death of the person depends on some philosophical preconception of what a person is. For example, Wikler suggests that the required definition of person is that of conscious agent or individual capable of social relations. But if philosophers do not agree, then philosophical claims remain disputable and negotiable. So how can death be defined?

The flip side of this problem is also, curiously enough, alluded to by Wikler when he alleges that sheer weight of medical opinion is not enough to resolve the question of defining death. True, most physicians now accept brain death as the medical standard. But adds Wikler, might not such an acceptance be a 'prejudice' or 'expedience'? He concludes that it is not enough that the majority of physicians accept the brain-death standard, what matters is whether this acceptance can be based on sound reasoning. Presumably, this is where philosophy comes in. But if philosophy remains controversial, then philosophy is not going to settle the matter - by itself - any more than medicine is. So we are back to where we started. How can death be defined?

We seem to be involved in a paradox. Medical standards on vital issues can always be questioned philosophically. But philosophy is, by its nature, a matter of controversy, and normally does not admit of closure on fundamental, vital issues. Each depends on the other, in a seemingly vicious circle.

The way to resolve the paradox is to realize that each of the fields of philosophy and medicine has its own special 'bite' on vital problems and issues. We must begin by emphasizing the strengths, rather than the weaknesses of each of these fields. First, we should note that when it comes to setting standard criteria for the determination of death, the sayso of medical consensus in the relevant medical fields is what matters. Reason: it is up to the medical profession to set standards for what constitutes good practice in regard to diagnosis and treatment. Hence, in effect, what the medical professional says is not merely 'prejudice', but is evidential fact.

Sometimes this self-evidencing nature of medical standards is frustrating to critics. On malpractice, for example, a claim that a doctor's practice was not 'standard and customary procedure' can only be decided in court with the help of other medical specialists in the same area. This self-confirmation of claims based on expertise sometimes seems circular, and perhaps in a sense it is.

What is the lesson of these remarks about evidence and medical ethics? It is that when it comes to setting standards, medical criteria for the determination 
of death, for example, it is the medical profession that must set these standards. That does not mean that the standards are forever closed. New evidence may come in, the medical profession may be divided by controversies, standards change and evolve, even admit of improvements. Medical standards may even be subject to philosophical criticism that plays a role in their evolution and improvernent.

The bottom line is that the doctors are the ones who must set the criteria for the determination of death. But these criteria presuppose certain philosophical principles and concepts, contestable ones in many cases. In this case, some target notion of the death of the person is presupposed. Where broad questions of public affairs come to the fore, philosophy must be involved, especially where anything so fundamental as the notion of the death of a person seems open to revision or questioning.

Here is where the distinction between concepts and criteria is absolutely vital. If medicine must set the criteria, philosophy must examine the deeper presumptions or implications of these criteria insofar as they relate to the concept of death as a fundamental ethical notion. The matter does not end with the setting of medical criteria, for the criteria rule when a person is dead, i.e., no longer has rights or responsibilities and may be declared a 'body" or 'corpse'. The implications here clearly intrude into areas of religion and philosophy. But there are a pluralism of religions, and some are not religious, or at any rate think religious pronouncements equally open to philosophical questioning as medical ones. Hence the need for philosophy.

But philosophy gives no final answers, only more questions. How then can an alliance between medicine and philosophy lead to anything of lasting practical or educational value if medicine leads to a consensus open to philosophical challenge, and philosophy yields no consensus at all, merely to contestable concepts? The question is itself a philosophical one, and may therefore be hoist by its own petard.

One way out of this maze is to concede that the job of philosophy is the humble one of articulating and clarifying the fundamental positions of disputants on issues of vital import. This process of discussion and criticism sometimes fails to lead to a decision tilt of the burden of proof to one side or the other, particularly if the dispute is of real and lasting philosophical interest. More often, it merely leads to the surfacing of 'hidden' assumptions. But this goal is sometimes itself quite valuable as an aid to consensus especially in a democratic society. Philosophy calls for the delicate skill of looking at both or all sides of an issue. And it does not necessarily fail if it does not immediately lead to agreement, or if it fails to support the one side decisively in a knock-down argument.

Hence we must make a distinction between being 'wishy-washy' or 'fuzzyminded' on the one hand, and carefully looking at both sides of an issue, on the 
other. Carefully and clearly formulating the arguments and concepts need not imply the cowardly avoidance of making a decision, or failing to confront definite conclusions. It could be that the right conclusion is that neither party is justified in its claims to being right. In such a case, picking a side for no good reason is not a mark of clear-mindedness or logically arriving at a decision or well-deliberated conclusion.

For all these reasons, the sayso of the philosopher is not the ultimate authority. Nor, as we saw above, when it comes to conceptual issues like re-defining the death of a person, can we take it that the sayso of the physician is the ultimate authority. The physicians have the ultimate authority to propound standard medical criteria for the determination of death. The philosophers have the somewhat uncertain authority of clarifying the conceptual issues posed by criteria to determine something as fundamental to everyman as the notion of the death of a person. They have the job of discussing whether these criteria can be justified as reasonable criteria for the death of a person.

So how does the feedback process between these two disciplines lead to a definition of death? The answer is that it hasn't so far. The best we can say is that the ongoing discussion is leading in a certain direction. The medical profession clearly has opted for brain-death criteria - procedures that determine irreversible destruction of the whole brain, including the brainstem. But there are different statements of these criteria, and many of them include the finding of irreversible cessation of circulatory and respiratory functions. This had led to uncertainty whether irreversible cessation of circulatory and respiratory functions is included in brain death or is a separate type of criterion for use in special cases, e.g., where a ventilator is not in use.

Legally, this ambivalence is reflected in different legislative wordings, some of which seem to suggest that irreversible cessation of flow of vital fluids represents a different type of criterion from brain death or even a different concept of death. What we have here is not unanimity, tout court. It is a movement away from traditional cardiorespiratory criteria to newer brain-based criteria - what philosophers of science call a paradigm shift.

Hence conceptual questions are raised. What is the 'real' meaning of death? Does it correspond more closely to the newer or the older criteria? Or should we compromise? The direction of the philosophical community also seems to be toward an acceptance of the notion of brain death. But there are specific worries. One is that if the person is defined in terms of the possibility of conscious activity, it seems more logical to some philosophers to postulate cerebral death as the matching clinical phenomenon. For to some it seems appropriate to locate the seat of conscious activity more narrowly in the cortex rather than in the whole brain. For these critics, including Wikler and Van Evra, brain death does not go far enough. 
The other problem, already mentioned, is posed by the possibility of artificial prolongation of the circulation of bodily fluids in the newly brain-dead. If they are dead, they are not persons, so perhaps it is logical to use them as organ* banks or for experimentation. Yet we are shocked at this conclusion. So it seems we should try better to say why, if we do truly and fully accept brain death as the death of the person. But the big conceptual controversies on brain death are yet to come. Philosophers have now proposed various competing theories of the death of a person. These theories reduce to five basic types, outlined in the last section of this essay. Some of them are further explicated by Van Evra, Thomasma and Kluge in this issue. But the step of showing how these concepts of death are linked to specific clinical parameters or sets of criteria has still not been fully carried out. It is an ongoing topic of philosophical research.

\section{CANADIAN VS: AMERICAN COMMISSIONS: A CONCEPTUAL OPPOSITION?}

One notable event has been the report of a US Presidential Commission on the Diagnosis of Death (President's Commission for the Study of Ethical Problems in Medicine and Biomedical and Behavioral Research). The model advocated by this Report (1981, Appendix F) is that of the Uniform Determination of Death Act (UDDA), worded as follows:

An individual who has sustained (1) irreversible cessation of circulatory and respiratory functions $s_{3}$ or (2) irreversible cessation of all functions of the entire brain, including the brain stem, is dead. A determination of death must be made in accordance with accepted medical standards.

The same wording has been endorsed by the American Academy of Neurology and the American Electroencephalographic Society. The report spells out in more specific terms what is meant by each phrase and clause of the above wording.

This model is the first one of the five discussed by Wallace-Barnhill et al. (1982), the type of model typified by the Kansas statute. The Commission Report $(1981$, p. 63) admits that the most troublesome aspect of this model is that by postulating two kinds of death, it offends public psychology. It seems you could be alive in one sense, yet dead in another! Yet the Report, as far as I can tell, does not indicate how this problem can be resolved.

Much simpler is the notion that there is just one basic determination of death, namely brain death, and that cessation of cardiac and respiratory function is merely one indicator or consequence of brain death. This is essentially the 
proposal of the Law Reform Commission of Canada (1979): irreversible cessation of brain function is given as the 'definition'. Then that standard can be met not only by direct measures of brain activity, but also by prolonged absence of respiratory and cardiac functions.

We might call the Presidential Commission Report (Kansas model) the binary model of death as opposed to the unary model of the Canadian Law Reform Commission. Model three of the scheme in Wallace-Barnhill et al. fits the Law Reform Commission wording, but model four, also including the word 'spontaneous' would fit the unary model as well. Which of these models is better? To answer this question, I think you have to be clear on what you mean by 'better in which respect'. Do you mean 'better as expressing a concept of death' or "better as offering a criterion for the determination of death'? Or do you mean something in between these alternatives?

One defence of the binary model is that it does not offer two separate concepts of the death of a person, but merely gives two criteria for the same concept. However, I do not think the UDDA wording above suggests this interpretation at all. Moreover, this wording does not seem to be a very good way to express a conceptual unity of death, if that is the intent. In fact, the wording strongly suggests or connotes the essential duality of death as a concept. Therefore this defence is not very convincing. In fact, the binary model expresses a pluralistic conception of the death of the person.

From a point of view of the philosophy it embodies, the binary view is on strong ground insofar as it defends the traditional religious conception that the body is a unity, and that the 'breath of life' is of vital significance. This viewpoint rejects the idea of singling out one organ, i.e., the brain, as the exclusive locus of humanhood. But is the binary view really giving priority to the brain, or does it balance the two notions of brain and circulation of vital fluids? Its very vagueness, which seems to allow it to (contradictorily) combine both viewpoints, is probably what makes it seem so plausible to many.

On the other hand, the unary view clearly gives priority to the brain. But it contains a vagueness too. It might be saying that the brain is the exclusive organ of life. Or it might merely be saying that brain death is the main criterion of death, but that other indicators may be used as well in order to determine the (undefined) concept of personal death. This potential vagueness takes some of the edge off the unary model as a flat statement of brain priority. For example, it is often said that a properly brain-dead patient dies after one week at the outside anyway - even with artificial respiration - so the brain criterion in effect incorporates the respiratory criterion as the basic finding. ${ }^{6}$

Despite the problems posed by the vagueness inherent in both models, $I$ think the unary model is more free of deeper philosophical confusion. It, for the most part, calls a spade a spade, whereas the binary model invites ambiguity. 
Proponents of the binary view should always be made to state unequivocally whether they intend to define concepts or criteria, and which of the two things - brain or cardiorespiratory function - is which. Unfortunately, they don't always do this, and the reader probably in most cases plugs in his own philosophical assumptions (or prejudices, if you like). ${ }^{7}$

The unary view also contains a seminal vagueness, but the imprecision is not so harmful. Usually we take the unary view to propound a brain-oriented concept of death where cardio-respiratory function remains as a criterion but plays no central conceptual role in the definition of death. This statement clearly expresses a philosophy that many would agree to, or at least be sympathetic with. Yet not everybody agrees. Some would still say that the brain is not the exclusive physical location of the whole person.

Once the philosophical cards are on the table, we can now clearly see that the President's Commission Report and the Canadian Law Reform Commission Report do indeed disagree. Each expresses a philosophical view of death that is contrary to the other, or can be so interpreted. We can see why the President's Commission thought that the Law Reform Commission of Canada had expounded a view that 'breaks with tradition' and might therefore offend some people. The fact that the Law Reform Commission statement has a secondary clause permit. ting absence of cardio-respiratory function as an additional criterion is cited by the President's Commission Report as a valuable and necessary adjunct. But even this addition is cited as "not good enough". The precise wording of this criticism is significant:

It would be possible, as in the statute drafted by the Law Reform Commission of Canada, to propound the irreversible cessation of brain functions as the "definition' and then to permit that standard to be met not only by direct measures of brain activity but also by the prolonged absence of spontaneous cardiac and respiratory functions'. Although conceptually acceptable (and vastly superior to the adoption of brain cessation as a primary standard conjoined with a nonspecific reference to other, apparently unrelated "usual and customary procedures'), the Canadian proposal breaks with tradition in a manner that appears to be unnecessary. For most lay people - and in all probability for most physicians as well - the permanent loss of heart and lung function (for example, in an elderly person who has died in his or her sleep) clearly manifests death. As previous chapters in this Report recount, biomedical scientists can explain the brain's particularly important - and vulnerable - role in the organism as a whole and show how temporary loss of blood flow (ischemia) becomes a pernanent cessation because of the damage it inflicts on the brain. Nonetheless, most of the time people do not, and need not, go through this two-step process. Irreversible loss of circulation is recognized as death because - setting aside any mythical connotations of the heart - a person without blood flow simply cannot live. Thus, the Commission prefers to employ language which would reflect the continuity of the traditional standard and the newer, brain-based standard (President's Commission Report, p. 74).

This paragraph reveals that the President's Commission found itself very deeply committed to the binary model as a philosophical principle. Thus they state that irreversible loss of circulation is itself recognized as death, that a person without 
blood flow 'cannot live'. It is quite clear that they are committed to a strong interpretation of the binary view which stipulates that there are two fundamental concepts of death. And it is quite significant that 'continuity of the traditional standard' is cited as the philosophical background of this view.

Here then is a clear and fundamental opposition. The Canadian Report expounds a unary view, but accepts cardiorespiratory function as a criterion. Brain death, however, is meant as the basic concept of the death of the person. The American Report expresses a basic dualism, according equal status to blood flow as a dual concept. Or does it? There's the rub. It also concedes that the Canadian wording is 'conceptually acceptable' and its own wording expresses a wish to emphasize the 'newer brain-based standard'. Is it really saying then that there are two standards (criteria), but perhaps only one underlying concept? I just can't tell from the way the Report is worded. I think that the Report strongly reflects the underlying ambiguity that the binary model tends to fall into. Clarification is still in order.

Which then commits the greater contravention of public psychology, the Canadian or the American report? Perhaps only a psychologist could say. But both contravene philosophical presumptions held by significant sectors of the public in many or most countries of the world. Although both are inherently fuzzy, I think the Canadian report is clearer. I also think that the wording of the American report persistently incorporates a deep ambiguity and is based on philosophical confusion. These problems are sure to surface in any public implementation of legislation based on such wording.

Perhaps it's better not to legislate at all - see Annas (1983) - but to legislate two potentially contrary concepts of death masked as a superficial unity, in the name of combining tradition and modern developments, is dead sure to lead to confusion. The whole idea that you can be dead in one way but still alive in another way is simply too grotesque and inconsistent to bear serious weight as an attempt at reform.

\section{CEREBRAL DEATH VS. BRAIN DEATH}

We should distinguish between those who reject cerebral death in principle as an inappropriate concept of death and those who reject it for practical reasons. For example, Negosvsky (1982) suggests that the concept of death as a human being should include the persistent vegetative state, but he adds the clause, 'if irreversibility can be proven' (p. 131). Thus Negosvsky accepts the concept, but questions its practicality as a criterion of death in relation to present medical knowledge. Others, like myself (1983) are inclined to question the concept of cerebral death as well, by raising the question of whether the appropriate 
physical location of what is characteristic of the living person can be equated with the cerebral cortex exclusively,

Hence the argument between those who favor cerebral death vs. those who favor whole brain death is not without certain subtleties. Some of us reject cerebral death for practical reasons, because irreversibility is not clearly estab. lished by the medical profession. Others balk at the idea of cerebral death in principle, rejecting the idea that the destruction of the cortex is the precise physiological area to equate with the death of the person.

There is a parallel ambivalence in the defences of those who reject whole brain death. Some argue that the idea is wrong in principle - that the whole brain is not the 'locus of life'. Some say it is too narrow, excluding circulation of bodily fluids, others say it is too wide and should be narrowed down to the cortex. Its defenders sometimes concede that it might be too narrow, but argue that cardiorespiratory standstill is a short-term consequence of proper brain death anyway, and so can be included in the latter (Korein 1978).

One notable difficulty in the project of equating death with cerebral death is the problem of irreversibility. There occasionally do occur cases where someone with apparently widespread cortical destruction suddenly comes out of the coma after a prolonged period of unconsciousness. The physiological explanation behind this phenomenon concerns the monitoring or gateway functions of the brainstem.

The reticular formation is a network of neural structures occupying the midventral portions of the medulla and midbrain. It contains ascending and descending components that regulate conditioned reflexes, sensory input, learning, and consciousness. It is possible that neocortical dysfunction could be due to impairments of the reticular formation. Moreover, it is quite possible that the healing of those impairments could re-activate formerly flat levels of electrical activity in the cortex of a damaged brain. For these reasons, it is quite possible for an injured patient to have a flat EEG and appear to all purposes to be permanently unconscious, even where the brainstem is still functional, yet at some later point come out of the coma and return to a normal life. With whole-brain death, there are no recorded instances of such recovery. But then whole-brain death includes irreversible destruction of the brainstem, and indeed all the contents of the intracranial cavity. But diagnosis of the apallic syndrome is still not a matter of reasonable certainty, and is still evolving. While we cannot say for certain that cerebral death is irreversible, brain death can effectively be diagnosed beyond reasonable doubt by existing medical standards.

While one does want to identify human personhood with the nexus of awareness and involvement in life, it may be dangerous to equate human life with consciousness, narrowly construed. Many memories and emotions are not at a conscious level, and the actual fact of consciousness is not always present, 
e.g., when one is asleep or unconscious. It is an improvement to say that personhood is to be equated with the possibility or capability for experience and activity, but this move requires that we state what is meant by 'possible'. In this sense, a fetus may have the possibility of experience or activity, even if it does not possess the actuality of these things. So much depends on what is meant by potential consciousness. ${ }^{8}$

For other reasons, it is dangerous to equate consciousness exclusively with the cerebral cortex. There is of course reason to connect consciousness with the structures of the cortex, but there may be even better established connections between consciousness and the brainstem. We know, for example, that integrating mechanisms of experience are present in the brainstem. Although it has long been a dogma of physiology that the cortex is the main area of intellectual activity and awareness, this view was strongly challenged by Penfield (1975), who argued that the indispensable substratum of consciousness lies in the higher brainstem. Penfield insisted that the area of grey matter in the higher brainstem is the highest brain mechanism, the area most closely related to mind and decision-making. He argued (p.38) that it is this area where cellular inactivation produces unconsciousness.

The principle of tutiorism advocates being on the safe side. Given the present state of medical knowledge of the brain, this principle dictates a preference of brain death over cerebral death as an irreversible criterion. But as Kluge points out in this issue, that is not the whole story. There is also the principle of justice or fairness. Many apallic syndrome patients survive for several years, and care for these patients is very expensive. If that apallic patient has no chance of recovery, we must ask whether it is fair to provide support facilities for the cerebrally dead at the expense of other areas of medical care and research that are badly underfunded. The principle of safety may conflict with the principle of justice in this instance. Moreover, Kluge argues that limits of expenditure should be adjusted downwards as the likelihood of benefit is reduced and there is known deprivation for others. By Kluge's reasoning, the balance should tilt towards the acceptance of cerebral death, all factors taken into account.

Cost containment is an increasing pressure in medicine, and perhaps one could even extend Kluge's argument here and question the justice of the amount we spend on critical care generally in the Western countries. From a cost-benefit point of view, preventative medicine and public education on health care could be a fairer maximization of health benefits. The issue is quite a general one, and hard to resolve ethically.

But in connection with defining death, we should note that recently there have been lawsuits where family argued that their next of kin died because the patient was not given adequate critical care treatment, e.g., it was alleged that intravenous nutrition ceased prematurely. ${ }^{9}$ If a criterion of cerebral death was 
made policy, and then occasional exceptions were found and made the basis of lawsuits, what good would the criterion be in the end? I doubt that it would save money, or have any very satisfactory practical benefits in the end. Diagnosing death under uncertainty would sponsor distrust of the motives of the medical profession. Any notion that death can be "speeded up" to save money would surely lead to bitter controversies and suspicions.

On the other hand, if cost containment by reduction of care for the irreversibly comatose is our goal, we can do that without declaring such patients 'dead'. As Newman and Jastremski make clear, the practice of withdrawing aggressive support in certain cases - where there is no hope in treatment and no wish to continue treatment - is already present in current accepted standards of intensive care. Treatment can be stopped where it is not needed or called for. And allowance for this practice is absolutely necessary as part of a humane and intelligent approach to medical care.

Hence there are two questions to be raised. First, whether adoption of cerebral death as a working criterion for death would lead to fairer allocation of health care benefits. And second, whether fairer distribution - say by allocating less money to some critical care cases - could better be achieved without switching from brain death to cerebral death as a general policy. These questions are sure to remain controversial, as the papers in the present issue indicate. Better criteria for irreversibility of cerebral death will sharpen these problems in the future.

\section{CONCEPTS OF DEATH}

One point of view is that death is not a moment or discrete event, but rather a process, a sequence along a continuum that may be vague in its boundaries. For example, Negosvsky (1982) describes clinical death as not a leap but a continuous process that comprises a "struggle" between the forces of $d y$ ing and resistance to dying. Morison (1971) also described death as a process, or vaguely bounded continuum.

If you take this point of view, then no set of criteria for death can precisely mark off the target process, because the process itself has fuzzy boundaries. Hence any set of criteria must be designed for over or underdetermination. The problem is to do this in a safe and ethically responsible manner. Criteria for death that are too narrow may lead to the error of treating the dead as living, and wasting resources on sustaining biological functions of the dead. The more grave danger however lies in the possibility of criteria that are too wide, with the possible result of treating a living person as dead. This latter is a repulsive and frightening possibility, and strongly contravenes the ethical principle of respect for persons. 
However, the point to be made here is that if death is a vaguely bounded process, there may be different sets of criteria that are equally adequate to rule out the errors of defining too widely or too narrowly. The criticism that a set of criteria is 'arbitrary' may therefore be not by itself a refutation of those criteria. For example, even if the set of criteria for brain death may seem on some philosophical grounds to be 'arbitrary' as a marker of personal death, that does not mean we should give up using brain death criteria.

There are five basic points of view you can take on death as a concept. According to the first and most elementary one, death is a moment. Some reflection will indicate that a moment is a kind of abstraction - it is a point of time that has no duration, or infinitely small duration. This abstraction may be hard for some to conceptualize, and so some are led on to think of as an event, a precisely bounded area of space and time. Some think of the event as a physical one, others think of it as an item of experience. Probably most of us tend to combine these two ways of thinking of it.

Traditionally, there was thought to be one 'moment' of death where the dying person gave a last gasp, but modern physiology has tended to make such an idea seem simplistic. Hence death is now often said, according to a third point of view to be a process, meaning a spectrum or continuous change that lacks sharply defined boundaries. Presumably then, there is a series of points in the continuum where the fading out of the vital functions become more and more irreversible. But there need be no single point of irreversibility per se, and there may be numerous vital functions involved in a sequential process of entropy.

An even more sophisticated conception of death sometimes evolves from the previous three through the recognition of the fundamental elusiveness of death as an experiential concept. Existentialists sometimes speak of death as 'the experience of nothingness' (le neant), but this is a peculiar metaphor. For at least on a secular notion of it, death is not experienced by the moriturus at all. Rather, it is the complete cessation of experience and destruction of the very subject of experience, the person. By this viewpoint, death is not an experience in life - for that would be a contradiction - but rather the limit of life.

Van Evra's paper in this issue forcefully expounds this point of view, following up a remark of Wittgenstein to the following effect: just as the limit of the visual field is not itself an item within the visual field, so death is not an item of experience in life. Hence death is not an event, but rather a limit, a construct we use in life to order and regulate our existence as temporal beings.

The viewpoint of death as limit is not by any means antithetical to a religious viewpoint, or other notions of survival or immortality. But certainly it is especially poignant on the secularly oriented assumption of the destruction of the subject of experience in death. Some like myself (1979) have questioned 
whether the view of death as limit can sustain the common and plausible notion that death is sometimes a bad thing, an object of negative value for the person who dies. For we often say of someone that, had he lived, his life would have been very valuable to him or others. Yet such talk seems to require a subject, a 'possible person' if you like, who suffered the harm of death. Yet if we are to be logically consistent, it seems hard to see how the negative view of death as limit could support the existence of some continuing 'possible person' who is the subject of counterfactual properties. Here then is an argument for a fifth conception of death as superimit, the possible projection beyond the limit of experience.

This fifth conception is not necessarily religious in essential character. For the possible persons who are the dead need not be 'alive' or 'experiencing' persons. They might merely be our projections of what would have been or could have been, had he survived. However, such iffy counterfactual abstractions are so difficult to understand with adequate clarity that some philosophers are inclined to reject this sort of talk altogether. Van Evra is one of these.

One epistemological fact about death is our lack of empirical access to it. It is an unknown. As Epicurus said, 'Where death is, we are not'. Our viewpoint on death is that of the living. Hence David Thomasma's paper in this issue makes an important criticism of philosophical attempts to define death metaphysically as the absence of life. Bryson's (1974) point is that what we conceive of as 'death' could be more accurately described as 'death as it is to the living'. Kant would have made the same point by his argument that there are essential limits to human empirical knowledge. Although we can have a certain moral knowledge or 'practical reasoning' of death, from a point of view of our experience and even our theoretical understanding, death is beyond the limits of knowledge. Hence, as Thomasma argues, the best we can try to do is describe death in terms of life as we know it.

Interestingly, Van Evra's conception of death as limit fits Thomasma's requirements quite well. Van Evra defines death as our way of ordering experience, knowing as we do that life has a finite bound in relation to our present line of experience. By this view, we can't extrapolate beyond the limit, but we can define death as the limit itself. The limit is the boundary of life, but seen from the side of life, as it were. All we really know is life, but we order life as a bounded sequence of states we live through. If this conceptualization is right, the metaphor of death as darkness is appropriate. But as Epicurus added, it may be childish to be afraid of the dark, if death (the limit) is not an event in life.

It is sometimes said, as a sort of homily, that in order to define death you need to define life, since death is the absence (negation) of life. This is not accurate, however. The period preceding birth is not 'death', yet it certainly is the absence of life. Thus death, according to Thomasma, is to be defined in 
relation to the living person. If the living person is a network of choices, activities, deliberations, a center of conscious awareness and action, then death is the termination of that network. So defined, death is the end-point of what one sees as the sequence of his future activities in this life, the finite bound of experience as we know it.

So the homily is partly right. Defining death as a concept presupposes a familiarity or engagement with the notion of a person (living person, human being). Death is the boundary at one end of that person in the nexus of human affairs in this world. Indeed, according to some - the discontinuous (secular) conception - death is the destruction and non-existence of the person. According to others death is a continuation of the same person in another form in a different nexus of experience than the one we are presently familiar with - the continuous (religious) conception. You don't have to be 'religious' to accept the second view, but it seems to help. Defining death as a concept need not strictly imply either one of these views. In fact the five ways of defining death we have considered do not imply the one view or the other as a matter of strict necessity.

What you do need, as Kluge reminds us, is to start with some preconception of what a 'person' is. All of us have some such preconception, but they are probably not very clear or unanimous amongst all of us. Hence the value of philosophical discussion.

DOUGLAS N. WALTON

The University of Winnipeg,

Department of Philosophy,

Winnipeg R3B 2E9, Manitoba, Canada

\section{NOTES}

1 See Carson Strong, 'The tiniest newborns', Hastings Center Report 13, 1983, 14-19.

2 A review of these matters is given in Walton (1983).

3 Willard Gaylin first drew public attention to this problem.

4 This example comes from H. L. A. Hart and A. M. Honore, Causation in the Law, Clarendon Press, Oxford, 1969.

5 The cases given by Michael Jastremski, in this issue, make this quite clear.

6 See Korein (1978), and also Cook and Hirsh (1982).

7 The traditional name for this ploy is equivocation.

8 Woods (1978) contains an excellent discussion of the notion of 'potential person' which deserves much wider attention than it has been given in the literature.

9 September 3, 1982, 'M.D.'s charged with murder', American Medical News 16.

\section{REFERENCES}

Annas, G. J.: 1983, 'Defining death: There ought to be a law', Hastings Center Report 13, $20-21$. 
Bryson, L.: 1974, 'Being and human death', The New Scholasticism 47, 343-350.

Cook, J. E., and Hirsh, L.: 1982, "The legal implications of brain death', Medicine and Law $1,135-151$.

Korein, J.: 1978, 'The problem of brain death: Development and history', Annals of the New York Academy of Sciences 315, 19-38.

Law Reform Commission of Canada: 1979, Criteria for the Determination of Death, Working Paper 23, Ottawa.

Morison, R. S.: 1971, 'Death: Process or event?', Science 173, 694-698.

Negosvsky, V.: 1982, 'Reanimatology today', Critical Care Medicine 10, 130-133.

Penfield, W.: 1975, The Mystery of the Mind, Princeton University Press, Princeton, N.J.

President's Commission for the Study of Ethical Problems in Medicine and Biomedical and Behavioral Research: 1981, Defining Death: A Report on the Medical, Legal and Ethical Issues in the Determination of Death, U.S. Government Printing Office, Washington, D.C.

Wallace-Barnhill, G., Roth, M. D., Briggs, B. A., Bastron, R. D., and Barrocas, A.: 1982, 'Medical, legal and ethical issues in critical care', Critical Care Medicine 10, 57-61.

Walton, D. N.: 1979, On Defining Death, MoGill-Queen's University Press, Montreal.

Walton, D. N.: 1980, Brain Death: Ethical Considerations, Purdue University Press, West Lafayette, Indiana.

Walton, D. N.: 1983, Ethics of Withdrawal of Life-Support Systems: Case Studies on Decision-Making in Intensive Care, Greenwood Press, Westport, Connecticut.

Woods, J.: 1978, Engineered Death, University of Ottawa Press, Ottawa. 